\title{
Flow Resistance Law in Channels with Flexible Submerged Vegetation
}

\author{
F. G. Carollo ${ }^{1}$; V. Ferro²; and D. Termini ${ }^{3}$
}

\begin{abstract}
In this paper, experimental data collected in a straight flume having a bed covered by grasslike vegetation have been used to analyze flow resistance for flexible submerged elements. At first, the measurements are used to test the applicability of Kouwen's method. Then, a calibration of two coefficients appearing in the semilogarithmic flow resistance equation is carried out. Finally, applying the $\Pi$-theorem and the incomplete self-similarity condition, a flow resistance equation linking the friction factor with the shear Reynolds number, the depth-vegetation height ratio and the inflection degree is deduced.
\end{abstract}

DOI: 10.1061/(ASCE)0733-9429(2005)131:7(554)

CE Database subject headings: Open channel flow; Flow resistance; Vegetation; Dimensional analysis.

\section{Introduction}

Evaluating flow resistance in a straight vegetated channel needs to take into account both the effects of the hydraulic cross section reduction and the dissipative effects due to the presence of the roughness elements (shape, size, arrangement, and concentration of the elements). In fact, both the geometry of the vegetation elements and the turbulence characteristics of the flow affect the hydrodynamic resistance and the size of the vortical wakes generated downstream of the elements themselves (Shen 1973; Ferro and Giordano 1992).

The hydraulic behavior of a single vegetation element which is completely submerged under the flow surface differs from an emergent one (Fig. 1). For both configurations, the case of flexible elements has to be distinguished from that of rigid elements (Fig. 1). From the application point of view, the grasslike vegetation can be considered flexible and, because of its small average height, it is usually completely submerged.

Shrubby vegetation is, instead, rigid and could assume both the emergent and the submerged configuration; a flood flowing in a channel can completely bend the rigid vegetation, often breaking and lying it down on the bed (Ferro 2002).

For rigid elements, the hydraulic behavior of the bed roughness is similar to that of a fixed bed formed by elements of known geometry (hemispheres, cubes, gravels, etc.) in large-roughness conditions (Kowobary et al. 1972; Shen 1973; Petryk and Bosma-

\footnotetext{
${ }^{1}$ Engineer, Dipt. di Ingegneria e Tecnologie Agro-Forestali, Facoltà di Agraria, Univ. di Palermo, Viale delle Scienze, 90128 Palermo, Italy.

${ }^{2}$ Full Professor, Dipt. di Ingegneria e Tecnologie Agro-Forestali, Facoltà di Agraria, Univ. di Palermo, Viale delle Scienze, 90128 Palermo, Italy. E-mail: vferro@unipa.it

${ }^{3}$ Researcher, Dipt. di Ingegneria Idraulica ed Applicazioni Ambientali, Facoltà di Ingegneria, Univ. di Palermo, Viale delle Scienze, 90128 Palermo, Italy.

Note. Discussion open until December 1, 2005. Separate discussions must be submitted for individual papers. To extend the closing date by one month, a written request must be filed with the ASCE Managing Editor. The manuscript for this paper was submitted for review and possible publication on August 16, 2002; approved on November 9, 2004. This paper is part of the Journal of Hydraulic Engineering, Vol. 131, No. 7, July 1, 2005. CASCE, ISSN 0733-9429/2005/7-554-564/\$25.00.
}

jian 1975; Ferro and Giordano 1990,1991; Baiamonte and Ferro 1997; Armanini and Righetti 1998; Stone and Shen 2002).

The flexible elements can assume different configurations (Kouwen et al. 1969; Gourlay 1970; Kowobary et al. 1972) due to both the hydrodynamic action of the flow and the bending stiffness $E I$, where $E$ is the longitudinal modulus of elasticity of the vegetation element and $I$ is the moment of inertia of the cross section of the element itself. Three different configurations have been experimentally observed for the flexible elements (Kouwen et al. 1969; Gourlay 1970):

1. Elements that are erect and do not change their position in time;

2. Elements that are subjected to a waving motion and, thus, change their position in time; and

3. Elements that assume permanently a prone position.

For each configuration (Fig. 1), different values of the inflection degree, i.e., the ratio between the bent vegetation height, $h_{s}$, and the vegetation height in the absence of flow, $H_{v}$, occur. In Case 1 , occurring for low values of flow velocity, the flexible elements assume a rigid behavior; in Cases 2 and 3, instead, the behavior of the vegetation elements depends on the bending stiffness EI. For low $E I$ values, the vegetation elements assume the prone position even when low values of flow velocity occur; by increasing the bending stiffness, i.e., if a more rigid vegetation is considered, higher values of flow velocity are necessary in order to reach a fixed inflection degree of the vegetation.

The measurements of the velocity profile, plotted as $u-y$, in which $u=$ local velocity and $y=$ height from the bottom, in the case of submerged flexible vegetation, have highlighted a typical $S$ shape of the velocity distribution (Fig. 2) (Kouwen et al. 1969; Carollo et al. 2002): for height from the bottom $y$ less than $h_{s}$, the local velocity becomes very low and assumes almost constant values (Gourlay 1970); near the top of vegetation $\left(y=h_{s}\right)$ both the local velocity and its gradient progressively increase, producing a vertical profile concave downward (Carollo et al. 2002); upon the vegetation $\left(y>h_{s}\right)$ the velocity gradients decrease with $y$ and the velocity profile is concave upward. Thus, the velocity profile shows an inflection point located at the top of vegetation $\left(y=h_{s}\right)$, where the maxima values of both the turbulent shear stress and the turbulence intensity appear (Ikeda and Kanazawa 1996; Carollo et al. 2002). 


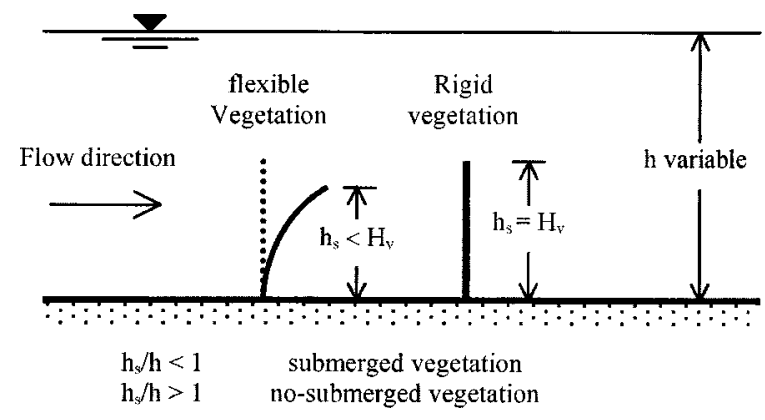

Fig. 1. Geometrical features of vegetation

Thus, the analysis of the velocity profile showed the presence of two regions of flow motion: one close to the bed, of thickness equal to the bent vegetation height, and a second one corresponding to the range $h_{s}<y<h$. The distinction of these two regions is more and more evident with increasing vegetation concentration, determined as the number $M$ of the vegetation elements per unit area, because a reduction of the momentum exchange between these two regions occurs (Kouwen and Li 1980).

Thus, evaluation of a flow resistance law for flexible vegetation is difficult because of the need both to estimate the bent vegetation height for each considered hydraulic condition and to take into account the influence of the vegetation concentration $M$. For a given type of vegetation, the evaluation of $h_{s}$ is complex for its dependence on the bending stiffness. In fact, the values of the longitudinal modulus of elasticity $E$ and of the moment of inertia $I$ depend on the plant growing phase and on the distance of the plant roots from the considered cross section (Longo 1997).

Among different methodologies proposed to estimate flow resistance in vegetated channels, Kouwen's method merits attention because of both its large experimentation (Kouwen and Unny 1973; Kouwen and Li 1980; Kouwen et al. 1981) and its theoretical basis founded on the biomechanical properties of the vegetation (Kouwen and Unny 1973; Kouwen and Li 1980; Kouwen 1988). Moreover, the Kouwen's approach was often used by other researchers (Masterman and Thorne 1992; Darby and Thorne 1996; Darby 1999) in order to predict the hydraulic behavior of the vegetation.

In this paper, first, Kouwen's method is reviewed. Then, the results of an experimental investigation carried out in a straight

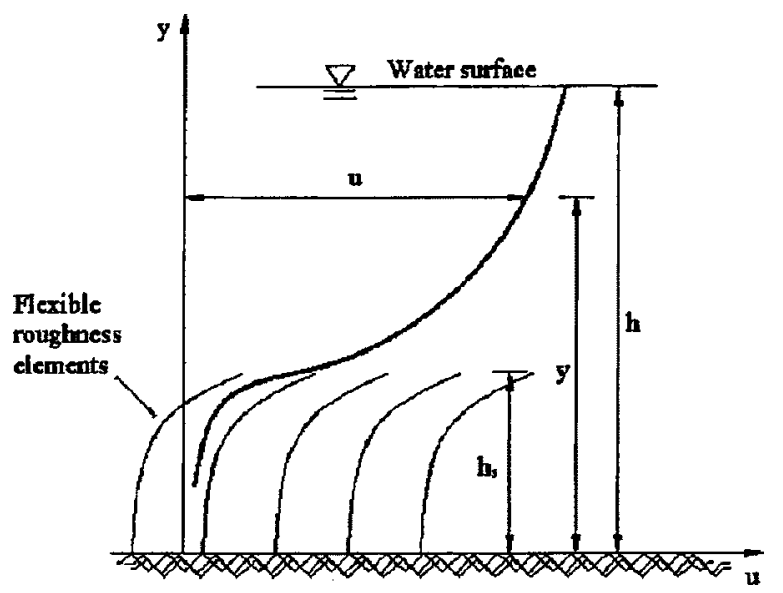

Fig. 2. Typical velocity profile in the case of submerged flexible vegetation (Carollo et al. 2002) laboratory flume with a bed covered by natural grasslike vegetation are reported. The experimental results have been used both to test the applicability of Kouwen's method for a natural flexible vegetation and to elaborate a new flow resistance law based on the self-similarity theory (Barenblatt 1979, 1987, 1993). This last flow resistance equation was also calibrated using the measurements recently carried out by Raffaelli et al. (2002) and Wilson and Horritt (2002).

\section{Review of Kouwen's Method}

Kouwen's method is based on some experimental results obtained in a straight laboratory flume with the bed covered by strips of plastic material (Kouwen and Unny 1973) whose hydraulic behavior, with regard both to the wave motion and to the inflexed configuration, is similar to that of a natural grasslike vegetation.

The method is based on the following hypothesis:

1. The flow resistance due to the bed, in which the vegetation is rooted, is negligible with respect to that due only to the vegetation elements (Fenzl and Davis 1964);

2. The vegetation elements are uniformly distributed on the bed (Kouwen and Unny 1973); and

3. The flow regime is fully turbulent.

Thus, aside from the vegetation configuration (prone or erect), Kouwen (1992) proposed the following flow resistance law:

$$
\frac{V}{u^{*}}=C_{0}+C_{1} \log \left(\frac{h}{h_{s}}\right)
$$

where $V=$ mean flow velocity; $u^{*}=$ shear velocity; and $C_{0}, C_{1}=$ two numerical coefficients. Eq. (1) has been previously deduced by Kouwen et al. (1969) [according to Rouse's observations (1965) and the velocity profiles observed by Gourlay (1970) in a channel covered with Kikuyu grass] integrating the logarithm velocity profile upon the vegetation layer. The flow resistance law (1) has been also recommended by the ASCE (1963) Task Force on Friction Factors in Channels.

Taking into account that, as aforesaid, in a vegetated channel the velocity profile does not follow the logarithm law but it is $S$ shaped, the semilogarithm form of Eq. (1) has to be considered a mere empirical deduction (Blench 1961).

Using the results of the dimensional analysis developed by Fenzl and Davis (1964), Kouwen and Unny (1973) proposed the following functional expression of the flow resistance law:

$$
\frac{V}{u^{*}}=\phi\left[\frac{H_{v}}{\left(\frac{M E I}{\gamma h S}\right)^{1 / 4}}, \frac{h_{s}}{H_{v}}, \frac{h_{s}}{h}\right]=\phi\left(B_{v}, \frac{h_{s}}{H_{v}}, \frac{h_{s}}{h}\right)
$$

in which $\phi=$ functional symbol; $\gamma=$ water specific weight; and $S=$ bed slope. In Eq. (2), the product of the concentration $M$ (number of stems per unit area) and the stiffness roughness of the vegetation elements, EI, represent the so-called aggregate stiffness.

The comparison between Eqs. (1) and (2) shows that the coefficients $C_{0}$ and $C_{1}$ depend on both the vegetation inflection degree, $h_{s} / H_{v}$, and the ratio $B_{v}=H_{v} /(M E I / \gamma h S)^{1 / 4}$ synthesizing the biomechanical characteristics of the vegetation (concentration and bending stiffness).

The vegetation inflection degree $\left(h_{s} / H_{v}\right)$ and the ratio $B_{v}$ are two different analytical expressions of the physical process of the inflection of the vegetated elements. Although their simultaneous presence in Eq. (2) would imply their functional independence 
Kouwen and Unny (1973) deduced, on the basis of experiments carried out in a straight laboratory flume with the bed covered by artificial elements (styrene sheet and lexan film) arranged in six different patterns, the following empirical relationship:

$$
\frac{h_{s}}{H_{v}}=0.14\left[\frac{\left(\frac{M E I}{\gamma h S}\right)^{1 / 4}}{H_{v}}\right]^{1.59}
$$

Eq. (3) was deduced using artificial vegetation which was characterized by a constant value of the stiffness along all the length of the vegetation element. Eq. (3) has been adopted by Kouwen and Unny (1973) to estimate the bent vegetation height, $h_{s}$, which is necessary to apply the resistance law (1). Eq. (3) can be written in the following form (Kouwen and Li 1980):

$$
M E I=\gamma h S\left[3.4 H_{v}\left(\frac{h_{s}}{H_{v}}\right)^{0.63}\right]^{4}
$$

which can be used to estimate the aggregate stiffness.

Introducing only one of the two dimensionless groups expressing the inflection vegetation process $\left(h_{s} / H_{v}\right.$ or $\left.B_{v}\right)$, the functional relationship (2) can be rewritten as follows:

$$
\frac{V}{u^{*}}=\phi_{1}\left(\frac{h_{s}}{H_{v}}, \frac{h_{s}}{h}\right)=\phi_{2}\left(B_{v}, \frac{h_{s}}{h}\right)
$$

in which $\phi_{1}$ and $\phi_{2}=$ functional symbols.

If Eq. (1) is used for expressing the mathematical shape of the functional relationship (5), then $C_{0}$ and $C_{1}$ must depend only on the inflection level of the vegetation that can be indifferently represented by the ratio $h_{s} / H_{v}$ or by $B_{v}$.

The experimental results obtained by Kouwen and Unny (1973) and by Kouwen and Li (1980), using vegetation elements of known stiffness, showed that the friction factor values increased with $M$. This result inductly demonstrates that the concentrations used for their experiments $\left(7.5-50 \mathrm{stems} / \mathrm{dm}^{2}\right)$ have to be considered moderate and surely less than the limit value $M^{*}$, corresponding to the quasismooth (skimming) flow regime, for which an invariance of the friction factor with the element concentration occurs (Ferro 1999).

In other words, Kouwen's results suggested using the aggregate stiffness as the representative variable of the total mechanical resistance of the vegetated layer because flow resistance was increasing with both stiffness and concentration of the vegetation elements. In other words, the use of the aggregate stiffness is based on the hypothesis that the concentration and the bending stiffness have a similar effect on flow resistance. Furthermore, their effects on the relative roughness could balance each other because of the contemporary increase in $M$ and decrease in $E I$ or vice versa (Kouwen and Unny 1973).

Kouwen and $\mathrm{Li}$ (1980), on the basis of experimental results obtained by Stoller and Lemon (1963), Kouwen and Harrington (1974), and Eastgate (1966), established that the vegetation shows a prone configuration when the shear velocity is higher than a critical value $u_{c}^{*}$. Thus, a flexible vegetation, with elastic behavior, can be classified as prone if the shear velocity $u^{*}$ is higher than the critical value, that can be estimated as

$$
u_{c}^{*}=0.028+6.33 M E I^{2}
$$

where $u_{c}^{*}$ is expressed in $\mathrm{m} / \mathrm{s}$; and $M E I$ in $\mathrm{Nm}^{2}$.

Eq. (6) has been deduced by Kouwen and Unny (1973), using experimental measurements carried out by artificial vegetation,

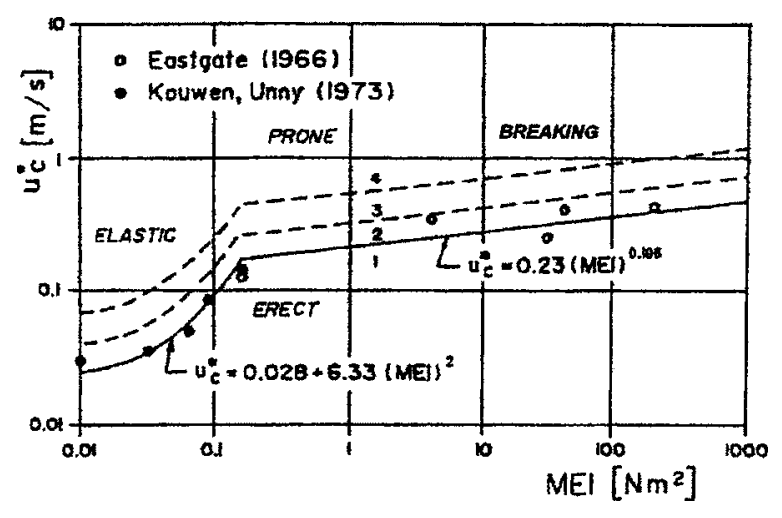

Fig. 3. Relationship between the critical shear velocity and aggregate stiffness [replotted from Kouwen et al. (1981)]

and connects with the following equation, determined by Eastgate's (1966) experimental data obtained for tall grass vegetation (Fig. 3):

$$
u_{c}^{*}=0.23 M E I^{0.106}
$$

The introduction of two different expressions of the critical shear velocity is justified by the following two different observed deformation behaviors of the vegetation:

1. For low values of the aggregate stiffness and, thus, for strongly deformable vegetation elements, the inflected elements show an elastic behavior and also the deformation is reversible. In other words, when flow finishes, the elements return to the nondeformed configuration; and

2. For high values of $M E I$, indeed, the inflection of the elements produces a plastic deformation and the stems remain in a bent configuration.

The analysis of flexible vegetation behavior developed by Kouwen and $\mathrm{Li}$ (1980) suggested the introduction of four types of vegetation configurations, passing from the erect configuration to

\begin{tabular}{|c|c|c|c|c|c|}
\hline \multirow[b]{2}{*}{$u^{*} / u_{c}^{*}$ range } & & \multicolumn{2}{|c|}{ Kouwen's method } & \multicolumn{2}{|c|}{$\begin{array}{c}\text { Recalibrated } \\
\text { Kouwen's method }\end{array}$} \\
\hline & & $C_{0}$ & $C_{1}$ & $C_{0}$ & $C_{1}$ \\
\hline Erect & $\frac{u^{*}}{u_{c}^{*}} \leqslant 1$ & 0.42 & 5.23 & 1.91 & 11.5 \\
\hline Prone & $1<\frac{u^{*}}{u_{c}^{*}} \leqslant 1.5$ & 0.57 & 7.64 & 4.63 & 22.4 \\
\hline Prone & $1.5<\frac{u^{*}}{u_{c}^{*}} \leqslant 2.5$ & 0.79 & 8.71 & 0.93 & 22.4 \\
\hline Prone & $\frac{u^{*}}{u_{c}^{*}}>2.5$ & 0.82 & 9.90 & -1.81 & 22.4 \\
\hline
\end{tabular}
the prone one (Zones 1, 2, 3, and 4 of Fig. 3), to which different values both of the ratio $u^{*} / u_{c}^{*}$ and of the coefficients $C_{0}$ and $C_{1}$ correspond, as reported in Table 1 . The ratio $u^{*} / u_{c}^{*}$, substantially

Table 1. $C_{0}$ and $C_{1}$ Coefficients of Eq. (1) 


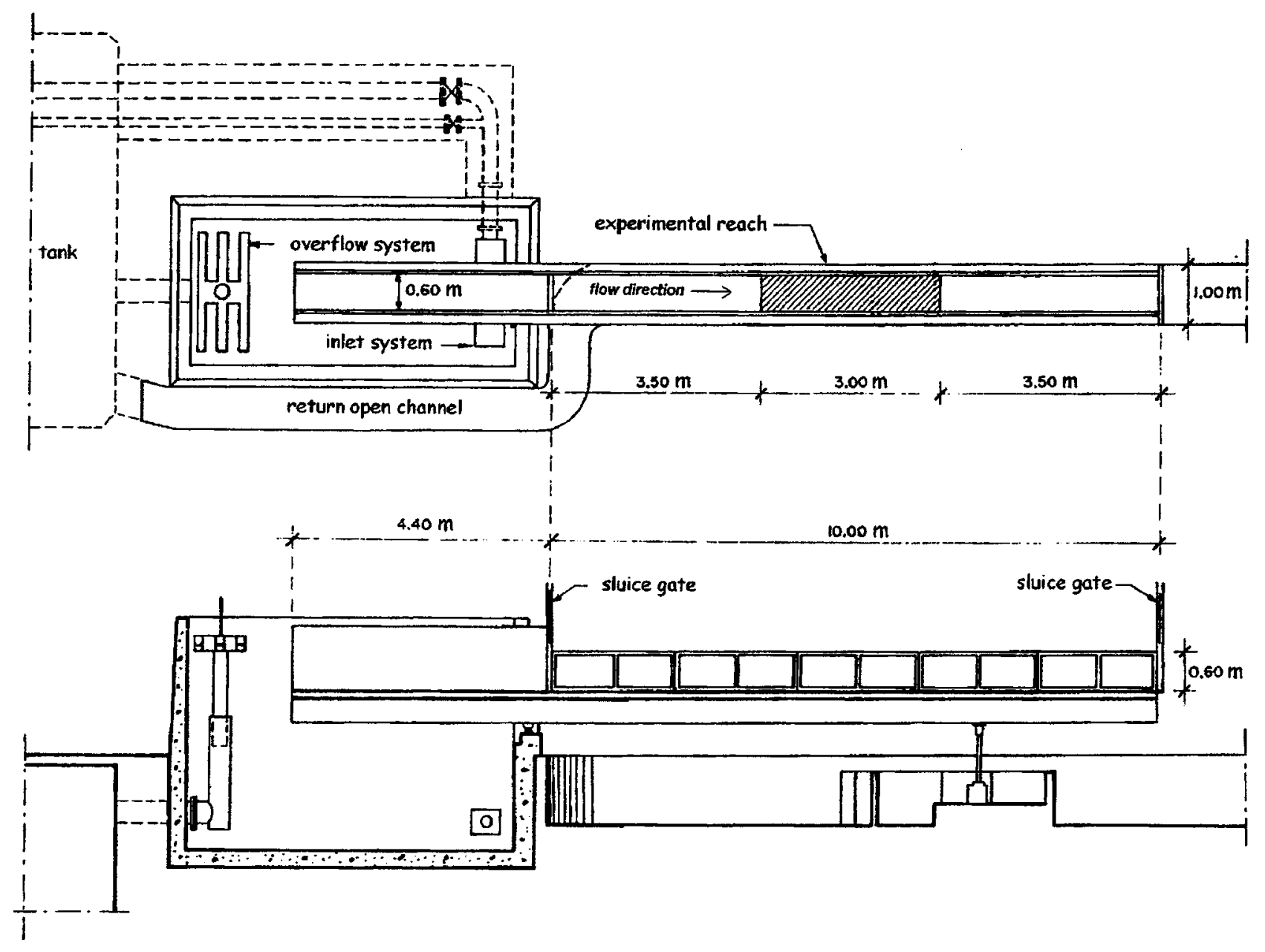

Fig. 4. Layout of the experimental installation
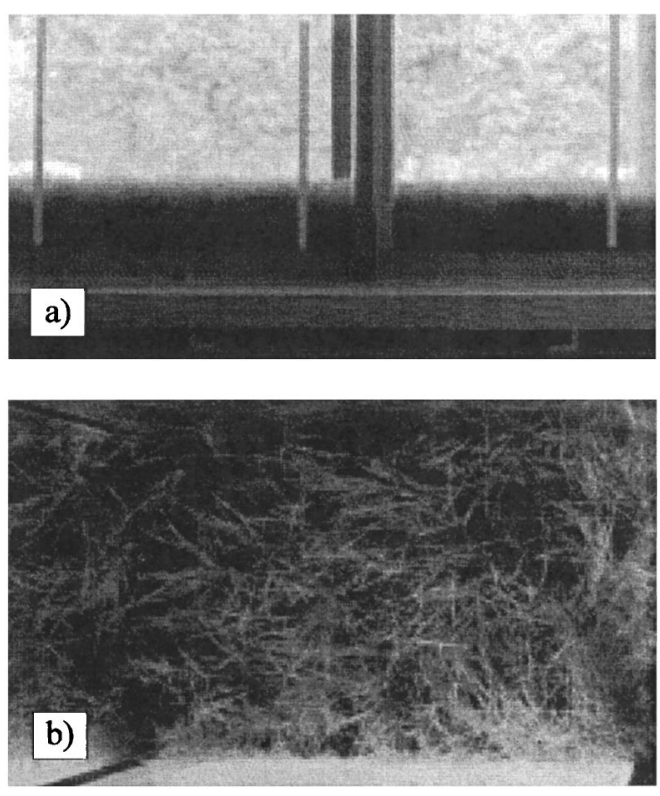

Fig. 5. Side (a) and top (b) views of the vegetated bed of the flume in the case of $440 \mathrm{stems} / \mathrm{dm}^{2}$ represents a different way to express the vegetation inflection degree $\left(h_{s} / H_{v}\right)$ and, thus, its introduction for coefficients $C_{0}$ and $C_{1}$ estimation is a substantial confirmation of the validity of Eq. (5).

In conclusion, the application of Eq. (1) needs the preliminary estimation of the critical value of the shear flow velocity by the aggregate stiffness using Eqs. (6) and (7). The critical value of the shear velocity is adopted as the minimum between the two calculated ones Then, the calculation of the ratio $u^{*} / u_{c}^{*}$ allows the evaluation of, according to the ranges listed in the first column of Table 1, the coefficients $C_{0}$ and $C_{1}$ of the resistance law (1).

\section{Experimental Installation and Measurement Technique}

The experimental runs were carried out in a rectangular straight laboratory channel of Dipartimento di Ingegneria Idraulica ed Applicazioni Ambientali at the Univ. of Palermo. The outlet and the inlet structures of the flume were connected to a hydraulic circuit, allowing a continuous recirculation of stable discharges. The flume, characterized by sloping bed, was $0.60 \mathrm{~m}$ wide and $14.4 \mathrm{~m}$ long (Fig. 4).

The water discharge was measured by an orifice plate installed in the feeding pipe. The measurement reach, located at $7.9 \mathrm{~m}$ from the entrance channel section, was $3 \mathrm{~m}$ long. The channel banks were rigid, while the channel bed was of grass (Fig. 5), produced by a mixture of stable Loietto $(50 \%)$, Festuca rubra 
Table 2. Characteristic Data of the Vegetated Beds Used

\begin{tabular}{lcc}
\hline Vegetated bed & $\begin{array}{c}M \\
{\left[\mathrm{stems} / \mathrm{dm}^{2}\right]}\end{array}$ & $\begin{array}{c}H_{y} \\
(\mathrm{~cm})\end{array}$ \\
\hline I & 280 & 11.5 \\
II & 310 & 11.0 \\
III & 440 & 20.0 \\
\hline
\end{tabular}

(40\%), and Poa pratensis (10\%). The resulting turf was composed by large ribbonlike stems about $4-5 \mathrm{~mm}$. The characteristic data of vegetation used are listed in Table 2.

The experimental runs were carried out for three vegetation concentrations $\left(M=280,310,440\right.$ stems $\left./ \mathrm{dm}^{2}\right)$, determined as the mean of stems per unit area, evaluated by 15 samples along the measurement reach. The water depth in the reach was estimated as the mean $h$ of four measurements carried out by a point gauge located at the vertical axis of four cross sections. The first cross section was at $90 \mathrm{~cm}$ downstream from the beginning of turf reach, and the following three cross sections had a relative distance of $40 \mathrm{~cm}$. The maximum difference between the water depth $h_{i}$ in the $i$ th cross section and the mean value $h$, was obtained for the first and the last cross sections. In these cross sections, the water depth $h_{i}$ was, on average, $\pm 7 \%$ from the value of $h$. In the other cross section, instead, the water depths $h_{i}$ were close to the mean value $h(0.99-1.02 h)$. The bent vegetation height, $h_{s}$, and nonsubmerged vegetation height, $H_{v}$, were estimated as the mean of three measurements by three decimal rules fixed to the flume wall.

The 80 experimental runs (Tables 3-5) were carried out varying, for each stem concentration, the flow rate $(12.0$ to $170.8 \mathrm{l} / \mathrm{s})$ and the flume bed slope $(0.1$ to $5.0 \%)$. The water depth measurements ranged from 6.10 to $27.19 \mathrm{~cm}$, which corresponded to depth-vegetation height ratio values ranging from 1.02 to 6.04 and Froude numbers varying from 0.22 to 0.73 . During experimental runs, the vegetation was always inflected, both prone and waving, and characterized by an inflection degree, $h_{s} / H_{v}$, ranging from 0.25 to 0.73 .

\section{Resistance Law for Flexible Submerged Vegetation}

First, in order to neglect the influence of the walls, the experimental values of the ratio $V / u_{*}$ have been corrected using the methodology proposed by Johnson (1942).

Fig. 6 shows, for two values of the bed slope, the pairs $\left[V / u^{*}, \log \left(h / h_{s}\right)\right]$ for given vegetation concentration $M$. The pairs $\left[V / u^{*}, \log \left(h / h_{s}\right)\right]$ obtained by Kouwen et al. (1969), using artifi-

Table 3. Experimental Data for the Vegetated Bed I

\begin{tabular}{lccc}
\hline$S$ & $\begin{array}{c}h \\
(\mathrm{~cm})\end{array}$ & $\begin{array}{c}V \\
(\mathrm{~cm} / \mathrm{s})\end{array}$ & $\begin{array}{c}h_{s} \\
(\mathrm{~cm})\end{array}$ \\
\hline 0.002 & 12.8 & 35.0 & 7.0 \\
0.002 & 16.3 & 52.1 & 5.7 \\
0.002 & 19.0 & 68.1 & 5.4 \\
0.002 & 20.2 & 75.7 & 5.1 \\
0.002 & 21.7 & 81.6 & 4.9 \\
0.002 & 23.1 & 87.0 & 4.8 \\
0.002 & 24.5 & 91.8 & 4.7 \\
0.002 & 25.8 & 97.6 & 4.4 \\
0.002 & 27.2 & 104.7 & 4.5 \\
\hline
\end{tabular}

Table 4. Experimental Data for the Vegetated Bed II

\begin{tabular}{|c|c|c|c|}
\hline$S$ & $\begin{array}{c}h \\
(\mathrm{~cm})\end{array}$ & $\begin{array}{c}V \\
(\mathrm{~cm} / \mathrm{s})\end{array}$ & $\begin{array}{c}h_{s} \\
(\mathrm{~cm})\end{array}$ \\
\hline 0.001 & 11.2 & 35.8 & 6.1 \\
\hline 0.001 & 12.1 & 38.3 & 6.0 \\
\hline 0.001 & 12.7 & 43.5 & 5.8 \\
\hline 0.001 & 13.5 & 47.1 & 6.0 \\
\hline 0.002 & 9.5 & 21.1 & 8.0 \\
\hline 0.002 & 11.2 & 35.8 & 6.0 \\
\hline 0.002 & 11.9 & 38.9 & 6.0 \\
\hline 0.002 & 12.4 & 44.6 & 5.8 \\
\hline 0.002 & 13.3 & 47.9 & 5.8 \\
\hline 0.005 & 9.2 & 21.8 & 7.8 \\
\hline 0.005 & 10.8 & 37.2 & 5.7 \\
\hline 0.005 & 11.5 & 40.3 & 5.9 \\
\hline 0.005 & 12.1 & 45.7 & 5.6 \\
\hline 0.005 & 12.9 & 49.3 & 5.6 \\
\hline 0.010 & 8.9 & 22.5 & 7.5 \\
\hline 0.010 & 10.1 & 39.7 & 5.2 \\
\hline 0.010 & 11.0 & 42.1 & 5.6 \\
\hline 0.010 & 11.6 & 47.7 & 5.5 \\
\hline 0.010 & 11.9 & 52.6 & 4.8 \\
\hline 0.010 & 12.2 & 52.2 & 5.4 \\
\hline 0.015 & 8.8 & 22.8 & 7.2 \\
\hline 0.020 & 8.5 & 23.6 & 7.0 \\
\hline 0.025 & 7.5 & 26.7 & 6.3 \\
\hline 0.030 & 7.2 & 27.8 & 5.8 \\
\hline 0.035 & 6.8 & 29.5 & 5.1 \\
\hline 0.040 & 6.5 & 30.8 & 4.8 \\
\hline 0.045 & 6.2 & 32.3 & 4.7 \\
\hline 0.050 & 6.1 & 32.9 & 4.6 \\
\hline
\end{tabular}

cial elements $5 \mathrm{~mm}$ long and $10 \mathrm{~cm}$ high with a concentration of $50 \mathrm{stems} / \mathrm{dm}^{2}$, are also reported in the same figure. Fig. 7 shows, for two different concentration values (310 and $440 \mathrm{stems} / \mathrm{dm}^{2}$ ), the pairs $\left[V / u^{*}, \log \left(h / h_{s}\right)\right]$ for given bed slope values.

The observation of both Figs. 6 and 7 suggests the following conclusions:

1. For given values of concentration and bed slope, Eq. (1) represents satisfactorily the relation between $V / u^{*}$, and the depth-vegetation height ratio $h / h_{s}$;

2. For a given concentration and for a fixed depth-vegetation height ratio, increasing the channel bed slope $V / u^{*}$ decreases and, thus, the flow resistance increases; and

3. In the range of the considered concentration values, an increase in $M$ implies a decrease in flow resistance.

Conclusion 2 is also justified by previous results of Gourlay (1970) who, representing Eastgate's measurements (1966) by the plot $V / u^{*}-\log \left(h / h_{s}\right)$, detected the same influence of channel slope.

Representing our experimental data by $n$-VR plots (Fig. 8) ( $n=$ Manning's coefficient and $R=$ hydraulic radius), we deduce $n$-VR curves similar to the ones obtained by Kouwen and $\mathrm{Li}$ (1980). In fact, Fig. 8 shows $n$ values increasing with the channel slope. In other words, in the $n$-VR plot, the behavior of our vegetation is similar to the one (plastic strips) investigated by Kouwen.

Conclusion 3 implies that, for the examined configurations (concentration values ranging from 280 to $440 \mathrm{stems} / \mathrm{dm}^{2}$ ), the quasi-smooth (skimming) flow regime occurs. Taking into 
Table 5. Experimental Data for the Vegetated Bed III

\begin{tabular}{|c|c|c|c|}
\hline$S$ & $\begin{array}{c}h \\
(\mathrm{~cm})\end{array}$ & $\begin{array}{c}V \\
(\mathrm{~cm} / \mathrm{s})\end{array}$ & $\begin{array}{c}h_{s} \\
(\mathrm{~cm})\end{array}$ \\
\hline 0.001 & 10.4 & 38.6 & 6.7 \\
\hline 0.001 & 11.0 & 42.1 & 7.2 \\
\hline 0.001 & 11.6 & 47.7 & 7.3 \\
\hline 0.001 & 12.3 & 52.7 & 7.1 \\
\hline 0.001 & 17.0 & 76.1 & 6.3 \\
\hline 0.001 & 19.8 & 90.3 & 5.9 \\
\hline 0.002 & 8.2 & 24.5 & 6.8 \\
\hline 0.002 & 10.3 & 39.0 & 6.5 \\
\hline 0.002 & 14.0 & 32.1 & 8.2 \\
\hline 0.002 & 14.6 & 34.4 & 8.0 \\
\hline 0.002 & 10.9 & 42.5 & 7.1 \\
\hline 0.002 & 11.5 & 48.1 & 7.2 \\
\hline 0.002 & 12.2 & 53.2 & 7.2 \\
\hline 0.002 & 17.8 & 72.5 & 7.0 \\
\hline 0.002 & 16.8 & 77.0 & 5.8 \\
\hline 0.002 & 19.9 & 88.8 & 6.3 \\
\hline 0.002 & 19.6 & 91.2 & 5.9 \\
\hline 0.005 & 8.1 & 24.8 & 6.8 \\
\hline 0.005 & 10.1 & 39.7 & 6.3 \\
\hline 0.005 & 10.7 & 43.3 & 7.0 \\
\hline 0.005 & 11.2 & 49.4 & 7.2 \\
\hline 0.005 & 11.9 & 54.5 & 6.5 \\
\hline 0.005 & 16.4 & 78.9 & 5.7 \\
\hline 0.005 & 19.1 & 93.6 & 5.8 \\
\hline 0.010 & 7.9 & 25.4 & 6.6 \\
\hline 0.010 & 9.8 & 41.0 & 6.2 \\
\hline 0.010 & 12.5 & 36.0 & 7.7 \\
\hline 0.010 & 10.3 & 45.0 & 7.0 \\
\hline 0.010 & 13.5 & 37.1 & 8.0 \\
\hline 0.010 & 10.8 & 51.2 & 7.1 \\
\hline 0.010 & 11.5 & 56.4 & 6.3 \\
\hline 0.010 & 16.8 & 77.0 & 6.6 \\
\hline 0.010 & 15.9 & 81.4 & 5.6 \\
\hline 0.010 & 18.3 & 96.4 & 5.9 \\
\hline 0.010 & 18.6 & 96.1 & 5.0 \\
\hline 0.015 & 7.6 & 26.4 & 6.5 \\
\hline 0.020 & 7.3 & 27.5 & 6.4 \\
\hline 0.025 & 7.1 & 28.3 & 6.4 \\
\hline 0.030 & 6.8 & 29.6 & 6.3 \\
\hline 0.035 & 6.7 & 30.0 & 6.2 \\
\hline 0.040 & 6.5 & 30.9 & 6.1 \\
\hline 0.045 & 6.4 & 31.4 & 6.1 \\
\hline 0.050 & 6.1 & 33.0 & 6.0 \\
\hline
\end{tabular}

account that the artificial elements used by Kouwen et al. (1969), with a concentration of $M=50 \mathrm{stems} / \mathrm{dm}^{2}$, showed both shape and transverse dimensions very similar to those of the vegetation elements used in the experiments analyzed in the present work, we can conclude that the limiting value $M^{*}$ identifying the quasismooth (skimming) flow regime falls inside the range $50-280$ stems $/ \mathrm{dm}^{2}$.

Fig. 9 shows, as an example, a possible relationship (boldface curve) between $V / u^{*}$ and the concentration $M$, for given values of the relative submergence $\left(h / h_{s}\right)$ and of the bed slope $(S)$. Fig. 9 clearly shows a discriminant value $M^{*}$, to which corresponds the minimum value of $V / u^{*}$. The no-boldface curve, also shown in
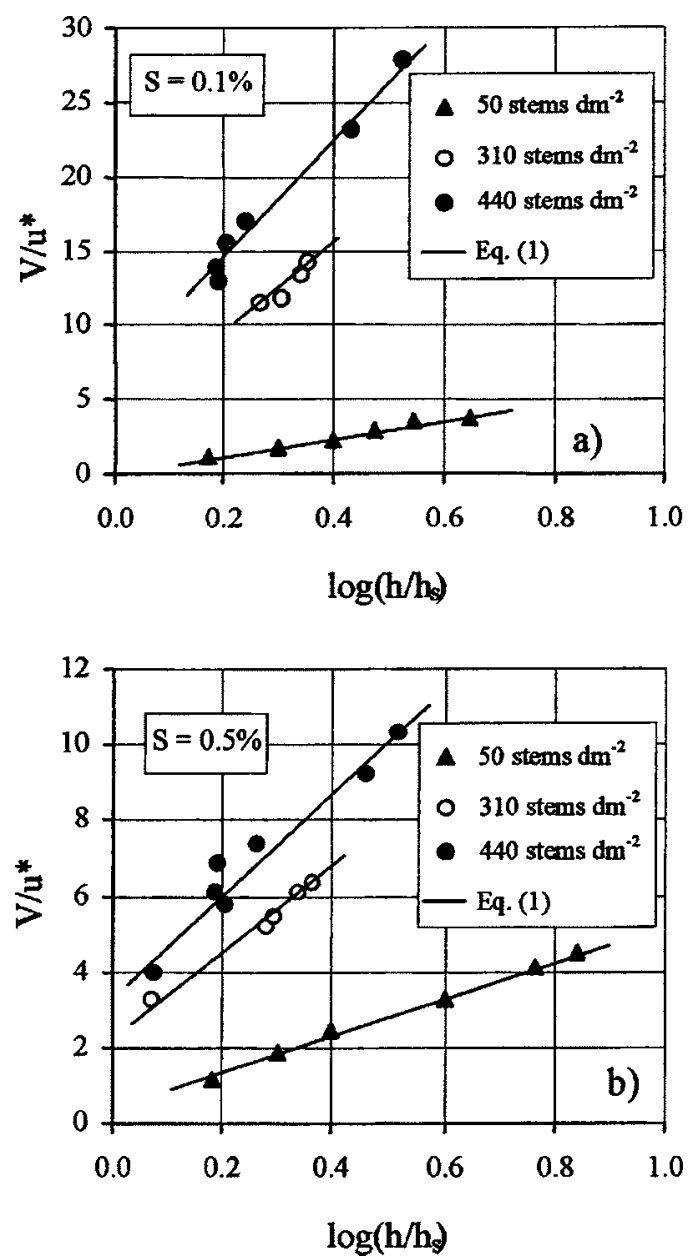

Fig. 6. Experimental pairs $\left(h / h_{s}, V / u^{*}\right)$, for a given bed slope $S$, corresponding to different concentration values

Fig. 9, represents a possible relationship between $V / u^{*}$ and $M$ satisfying the hypothesis that the flow resistance increases monotonously with the concentration, as deduced by Kouwen. As shown in Fig. 9, these two curves give different values of $V / u^{*}$ for $M>M^{*}$, and this difference gradually increases as increasing values of $M$ are considered. The experimental data, obtained for different bed slope and concentrations, have been first used to verify the applicability of Kouwen's method.

Because no specific evaluation of the bending stiffness of the vegetation used for the experiments has been made, the aggregate stiffness $M E I$ has been estimated, for each of the 80 experimental runs, by Eq. (4). Then, using Eq. (6) or (7), the corresponding values of $u_{c}^{*}$ have been estimated. Finally, using the estimated ratio $u^{*} / u_{c}^{*}$, the values of the coefficients $C_{0}$ and $C_{1}$ of Eq. (1) have been determined (Table 1).

Fig. 10 shows the comparison between the experimental values of $V / u^{*}$ and the calculated ones using the Kouwen's method. This method produces a systematical underestimation of $V / u^{*}$ which is greater as the vegetation concentration increases.

The overestimation of the flow resistances is due, as Fig. 9 shows, to the circumstance that the Kouwen's method is based on the hypothesis that the $V / u^{*}$ decreases for increasing values of the concentration.

In order to correct this distortion, assuming Eqs. (4), (6), and (7) are valid for each of the four ranges of $u^{*} / u_{c}^{*}$ (Table 1), the values of the coefficients $C_{0}$ and $C_{1}$ minimizing the sum of the 

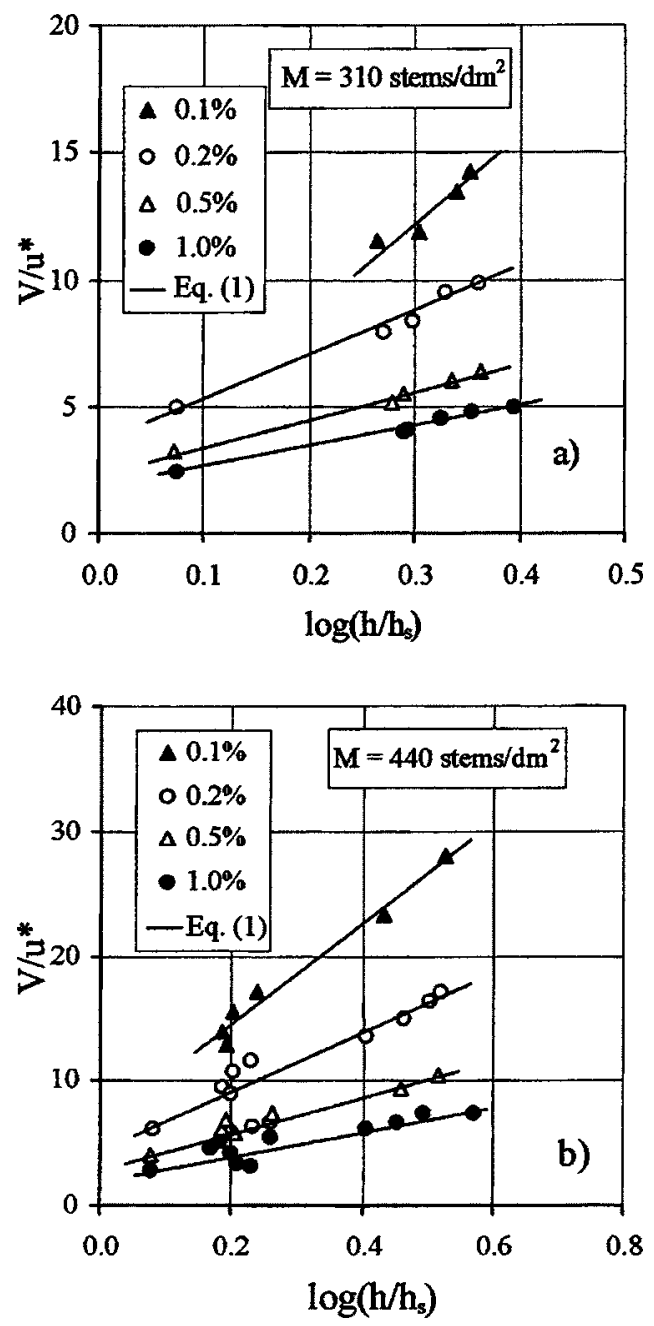

Fig. 7. Experimental pairs $\left(h / h_{s}, V / u^{*}\right)$, for a given concentration, corresponding to different bed slope values, $S$

squares of the differences between the measured $V / u^{*}$ values and the calculated ones have been estimated. The estimated values of $C_{0}$ and $C_{1}$, also reported in Table 1 , highlight that $C_{0}$ strongly depends on the particular considered configuration, while $C_{1}$ assumes a constant value for all prone configurations which is approximately double the value corresponding to the erect configuration.

In Fig. 11, the comparison between the experimental values of $V / u^{*}$ and the calculated ones using Kouwen's method, with the "calibrated" coefficients $C_{0}$ and $C_{1}$, is reported. Fig. 11 shows that with the exception to the case of high concentration $\left(440 \mathrm{stems} / \mathrm{dm}^{2}\right)$, the points are close to the line of perfect agreement.

For a rigid and straight prismatic channel, for a flow without sediment transport, assuming that the vegetated elements are uniformly distributed and neglecting the dissipative effects due to the soil where the vegetation is rooted, the application of $\Pi$-theorem (Barenblatt 1979 ) allows the expression of the flow resistance law by the following functional relationship:

$$
F\left(V, u^{*}, \rho, \mu, H_{v}, E I, h, M\right)=0
$$

where $\mu=$ water viscosity; $\rho=$ water density; and $F=$ functional symbol.
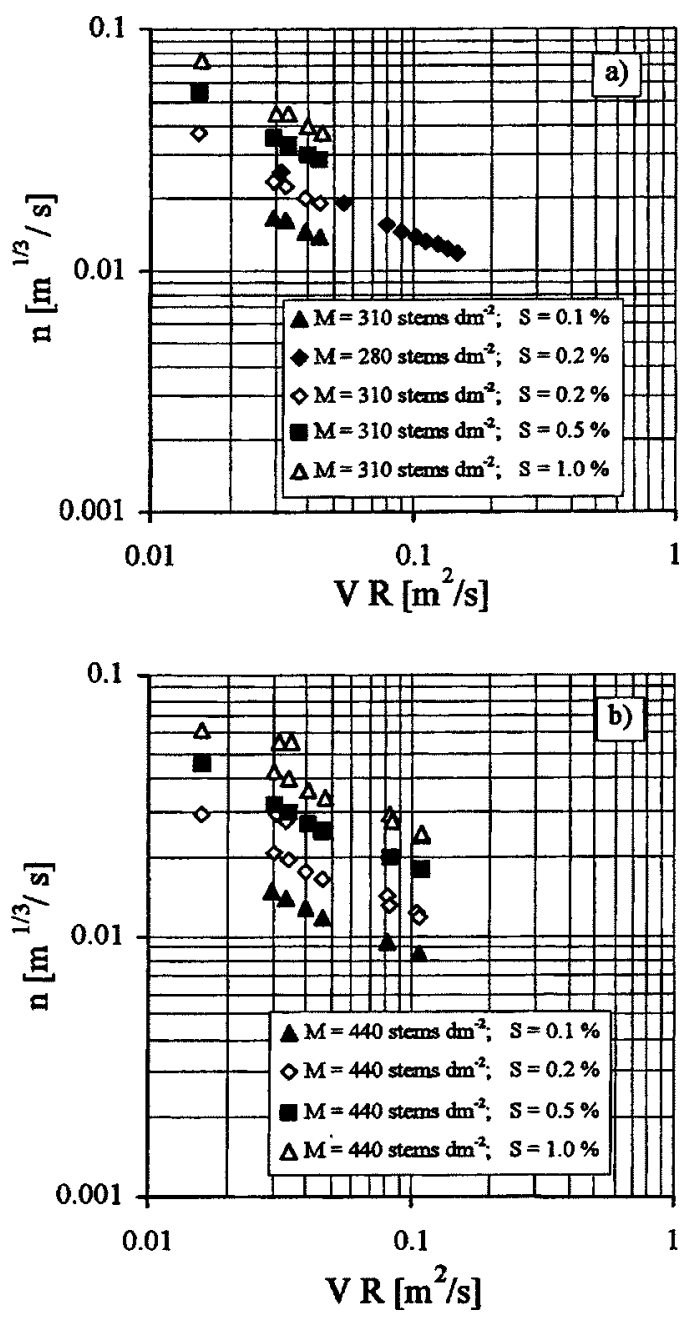

Fig. 8. Experimental pairs $(V R, n)$, for concentration values equal to (a) 280-310; and (b) $440 \mathrm{stems} / \mathrm{dm}^{2}$, corresponding to different bed slope values, $S$

Taking into account that the bending stiffness $E I$ affects the vegetation inflection degree $\left(h_{s} / H_{v}\right)$, Eq. (8) can be rewritten as follows:

$$
F_{1}\left(V, u^{*}, \rho, \mu, H_{v}, h_{s}, h, M\right)=0
$$

in which $F_{1}=$ functional symbol.

The application of the П-theorem allows expression of Eq. (9) using five dimensionless terms as follows:

$$
\frac{V}{u^{*}}=f\left(\frac{u^{*} h_{s}}{v}, \frac{h}{h_{s}}, \frac{H_{v}}{h_{s}}, M\right)=0
$$

where $f=$ functional symbol; $v=$ kinematic viscosity; and $M$ has to be considered equal to the ratio $M / M_{0}$ in which $M_{0}$ is a reference concentration set equal to $1 \mathrm{stem} / \mathrm{dm}^{2}$.

As it is known a physical phenomenon follows the complete self-similarity condition (Barenblatt 1979,, 1987, 1993; Ferro 1997; Ferro and Pecoraro 2000) for a given dimensionless group $\Pi_{n}$ if the functional relationship $\Pi_{1}=\varphi\left(\Pi_{2}, \Pi_{3}, \ldots, \Pi_{n}\right)$ representing the considered phenomenon, in which $\Pi_{1}, \Pi_{2}, \Pi_{3} \ldots \Pi_{3}$ $=$ dimensionless groups, is independent of $\Pi_{n}$.

The self-similar solutions can be found analyzing the function $\varphi$ for $\Pi_{n} \rightarrow 0$ or $\Pi_{n} \rightarrow \infty$; if the function tends to a finite limit different from zero, the self-similarity is called complete; if the 


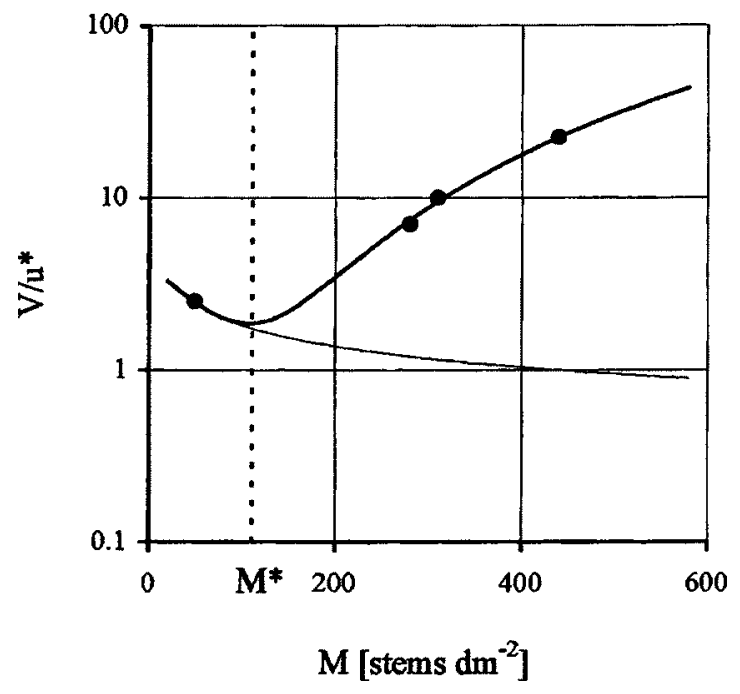

Fig. 9. Relationship between $V / u^{*}$ and the stem concentration

function assumes a limit value equal to zero or to infinity, the self-similarity is incomplete and the phenomenon is described by the following relationship (Barenblatt 1979, 1987):

$$
\Pi_{1}=\Pi_{n}^{\delta} \cdot \varphi_{1}\left(\Pi_{2}, \Pi_{3}, \ldots, \Pi_{n-1}\right)
$$

in which $\delta=$ numerical constant; and $\varphi_{1}=$ functional symbol.

Therefore, assuming an incomplete self-similarity condition for the groups $h / h_{s}, u^{*} h_{s} / v$, and $H_{v} / h_{s}$, Eq. (10) gives the following resistance law:

$$
\frac{V}{u^{*}}=A_{0}(M)\left(\frac{h}{h_{s}}\right)^{a_{1}}\left(\frac{u^{*} h_{s}}{v}\right)^{a_{2}}\left(\frac{H_{v}}{h_{s}}\right)^{a_{3}}
$$

where $a_{1}, a_{2}, a_{3}=$ numerical coefficients that have to be determined using the available measurements; and $A_{0}(M)=$ unknown function of $M$ that assumes, for a given concentration, a constant value.

For each concentration value $(50,280,310$, and $\left.440 \mathrm{stems} / \mathrm{dm}^{2}\right)$, Eq. (12) has been arranged to the available experimental data in order to estimate the 4 coefficients $A_{0}, a_{1}, a_{2}$, and $a_{3}$. The estimation procedure was carried out imposing that

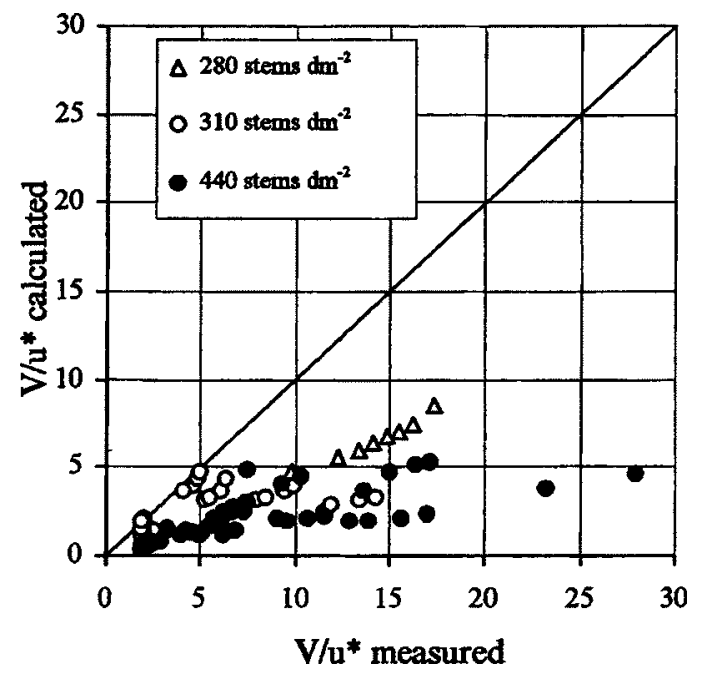

Fig. 10. Comparison between the measured values of $V / u^{*}$ and those calculated by Kouwen's method

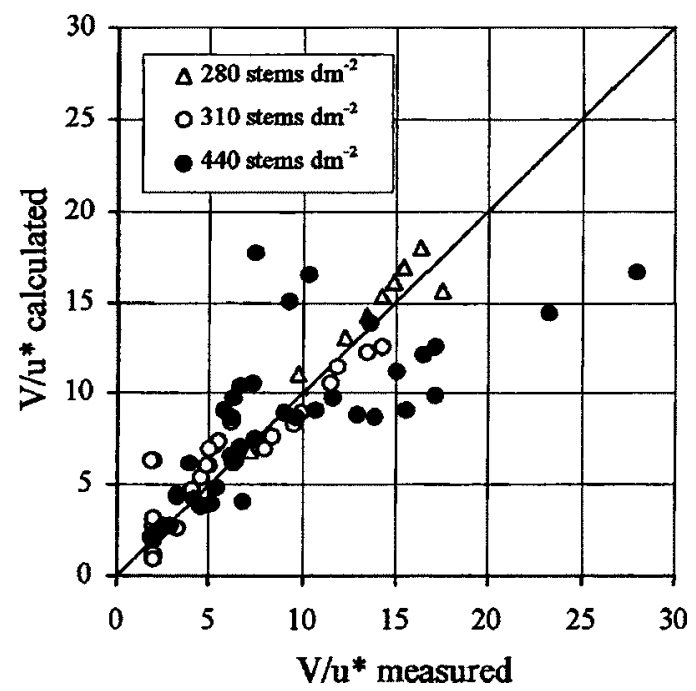

Fig. 11. Comparison between the measured values of $V / u^{*}$ and those calculated by calibrated Kouwen's method

each numerical coefficient $a_{1}, a_{2}$, and $a_{3}$ assumes the same value (according to the hypothesis of incomplete self-similarity) for the four considered configurations and that only $A_{0}$ depends on the concentration $M$. The estimated values of $A_{0}, a_{1}, a_{2}$, and $a_{3}$ coefficients are listed in Table 6.

In Fig. 12, the experimental values of $V / u^{*}$ and the calculated ones by Eq. (12) with the coefficient values listed in Table 6, are plotted. Fig. 12 shows that the points referring to the experiments carried out by Kouwen et al. (1969) show the greatest dispersion from the line of perfect agreement.

This poor agreement of Eq. (12) to Kouwen's experimental data can be attributed to the dependence on the term $u^{*} h_{s} / v$, that is presented in Eq. (12) but was not taken into account by Kouwen.

In order to verify this hypothesis, Eq. (12) has been rearranged using only Kouwen et al.'s experimental data (1969) and assuming $a_{1}=1.168$ and $a_{3}=-0.861$. The fitting of Eq. (12) to the experimental data was obtained by $A_{0}=0.368$ and $a_{2}=0.086$. The value of $a_{2}$ is almost equal to zero confirming the substantial nondependence of Kouwen's data (1969) on $u^{*} h_{s} / v$. Finally, fitting Eq. (12) — by $a_{1}=1.168, a_{2}=0$, and $a_{3}=-0.861$ - to the experimental data of Kouwen, the value $A_{0}=0.780$ was estimated.

In Fig. 13, the comparison between the experimental values of $V / u^{*}$ and the calculated ones by Eq. (12) is reported. In this last case, the coefficients reported in Table 6 are used for the concentrations 280, 310, and $440 \mathrm{stems} / \mathrm{dm}^{2}$, while $A_{0}=0.780, a_{1}$ $=1.168, a_{2}=0$, and $a_{3}=-0.861$ are assumed for the concentration of $50 \mathrm{stems} / \mathrm{dm}^{2}$.

Therefore, the analysis suggests that the dimensionless term $u^{*} h_{s} / v$ has to be considered in the flow resistance law only when

Table 6. Coefficients of Eq. (12) Corresponding to Different Concentration Values

\begin{tabular}{lcccc}
\hline $\begin{array}{l}M \\
\left(\mathrm{stems} / \mathrm{dm}^{2}\right)\end{array}$ & $A_{0}$ & $a_{1}$ & $a_{2}$ & $a_{3}$ \\
\hline 50 & 4,674 & 1.168 & -1.023 & -0.861 \\
280 & 17,948 & 1.168 & -1.023 & -0.861 \\
310 & 21,127 & 1.168 & -1.023 & -0.861 \\
440 & 51,138 & 1.168 & -1.023 & -0.861 \\
\hline
\end{tabular}




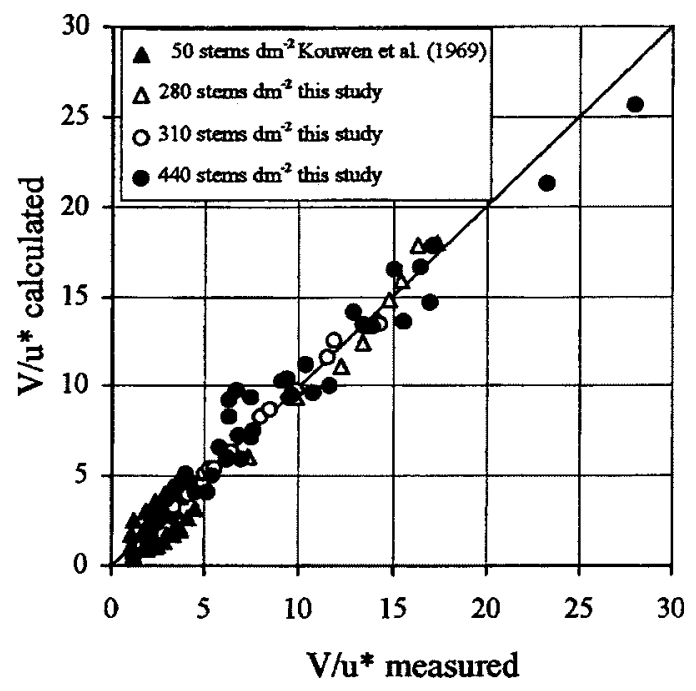

Fig. 12. Comparison between the measured values of $V / u^{*}$ and those calculated by Eq. (12) using coefficients listed in Table 6

high values (greater than a limit value falling in the range of $50<M<280$ stems $/ \mathrm{dm}^{2}$ ) of the vegetation concentration occur. This result can be justified taking into account that, according to Gourlay (1970) and Kouwen et al. (1969), the flow velocity inside the vegetated layer can be deduced from the shear velocity; in this case, the dimensionless term $u^{*} h_{s} / v$ is the Reynolds number of the flow inside the vegetated layer of thickness equal to $h_{s}$. Since by increasing the concentration $M$ an appreciable decreasing in flow velocity inside the vegetated layer occurs, the study of the dissipative phenomena has to take into account the shear Reynolds number.

For validating the flow resistance law (12) in the range of $M \leqslant 50$ stems $/ \mathrm{dm}^{2}$ adopting the coefficients $a_{1}=1.168, a_{2}=0$, and $a_{3}=-0.861$, the measurements carried out by Raffaelli et al. (2002) and Wilson and Horritt (2002) were also used.

The experimental runs of Raffaelli et al. (2002) were carried out in a sloping flume (slope equal to 0.006) using plastic elements simulating the behavior of the natural plant "Isolepsis." A

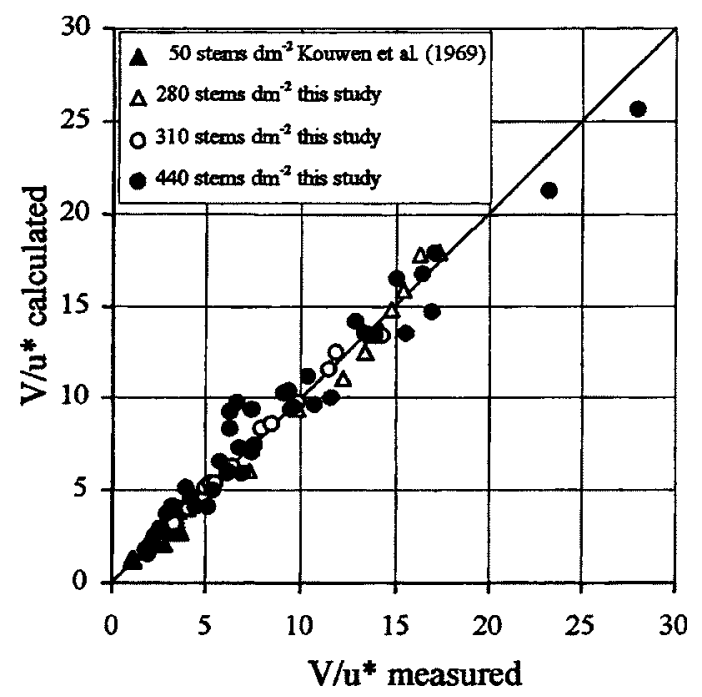

Fig. 13. Comparison between the measured values of $V / u^{*}$ and those calculated by Eq. (12) using coefficients listed in Table 6 for $M \geqslant 280 \mathrm{stems} / \mathrm{dm}^{2}$

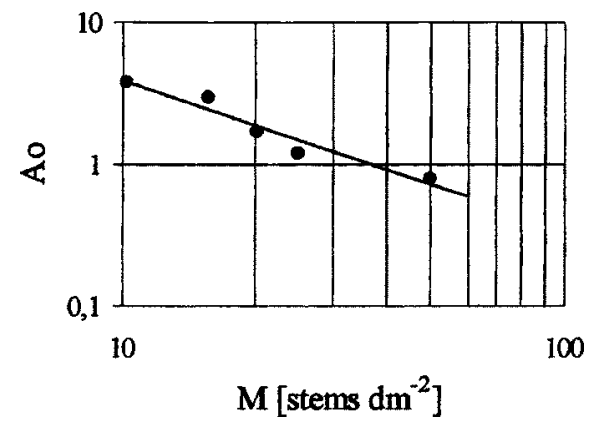

Fig. 14. Relationship between the scale factor $A_{0}$ of Eq. (12) and the vegetation concentration for low $M$ values

vegetation height $H_{v}$ equal to $0.13 \mathrm{~m}$ and three concentration values $\left(10.20,15.60\right.$, and $\left.20.40 \mathrm{stems} / \mathrm{dm}^{2}\right)$ were employed.

Wilson and Horritt (2002) carried out an experimental study using a sloping flume (slope equal to 0.001) and a submerged flexible vegetation (common garden grass) with a vegetation height in the absence of flow, $H_{v}$, equal to $0.07 \mathrm{~m}$ and a vegetation concentration equal to $25.0 \mathrm{stems} / \mathrm{dm}^{2}$.

The values of the $A_{0}$ coefficients, estimated by applying Eq. (12) with $a_{1}=1.168, a_{2}=0$, and $a_{3}=-0.861$ (low concentrations, $M \leqslant 50$ stems $/ \mathrm{dm}^{2}$ ) and a least-squares technique, are listed in Table 7. In the same table, the values of $A_{0}, a_{1}, a_{2}$, and $a_{0}$ for the case "high concentrations" $280 \mathrm{stems} / \mathrm{dm}^{2}$ are also listed. The following power relationships can be fitted to the pairs $\left(M, A_{0}\right)$ :

$$
A_{0}=43.4 M^{-1.0521}
$$

for $M \leqslant 50$ stems $/ \mathrm{dm}^{2}$ (Fig. 14) and

$$
A_{0}=0.0275 M^{2.3701}
$$

for $M \geqslant 280$ stems $/ \mathrm{dm}^{2}$ (Fig. 15).

The comparison between measured and calculated friction factor values (Fig. 16) shows good agreement for the available experimental vegetation data set.

In conclusion, Eq. (12) can be used for estimating the flow resistance for flexible submerged vegetation. If the geometric characteristics of both the vegetation (vegetation concentration $M$, bending stiffness $E I$, and height in absence of flow $H_{v}$ ) and the channel (slope and cross section geometry) are known, then determining the friction factor requires [by Eq. (12)] the estimate of the bent vegetation height $h_{s}$ that can be evaluated by Eq. (3). Therefore, for a given value of water depth, $u^{*}=\sqrt{g h S}$ and $h_{s}$ [Eq. (3)] values can be calculated, and by introducing them into Eq. (12) -with $a_{1}=1.168, a_{2}=0$ (for $M \leqslant 50 \mathrm{stems} / \mathrm{dm}^{2}$ ) or $a_{2}=$

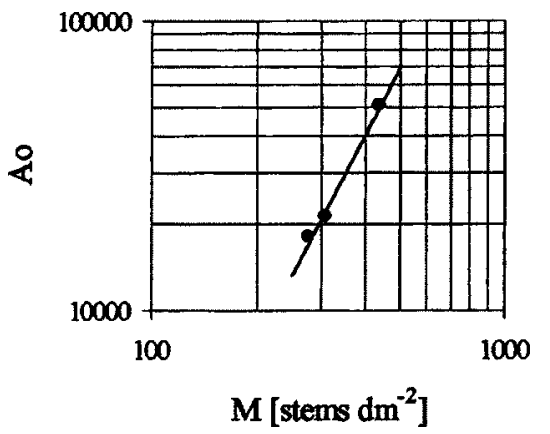

Fig. 15. Relationship between the scale factor $A_{0}$ of Eq. (12) and the vegetation concentration for high $M$ values 
Table 7. Coefficients of Eq. (12) Corresponding to Different Concentration Values

\begin{tabular}{|c|c|c|c|c|c|}
\hline Source & $\begin{array}{c}M \\
\left(\text { stems } / \mathrm{dm}^{2}\right)\end{array}$ & $A_{0}$ & $a_{1}$ & $a_{2}$ & $a_{3}$ \\
\hline Raffaelli et al. (2002) & 10.2 & 3.715 & 1.168 & 0.000 & -0.861 \\
\hline Raffaelli et al. (2002) & 15.6 & 2.941 & 1.168 & 0.000 & -0.861 \\
\hline Raffaelli et al. (2002) & 20.4 & 1.708 & 1.168 & 0.000 & -0.861 \\
\hline Wilson and Horritt (2002) & 25 & 1.184 & 1.168 & 0.000 & -0.861 \\
\hline Kouwen et al. (1969) & 50 & 0.780 & 1.168 & 0.000 & -0.861 \\
\hline This work & 280 & 17,948 & 1.168 & -1.023 & -0.861 \\
\hline This work & 310 & 21,127 & 1.168 & -1.023 & -0.861 \\
\hline This work & 440 & 51,138 & 1.168 & -1.023 & -0.861 \\
\hline
\end{tabular}

-1.023 (for $M \geqslant 280 \mathrm{stems} / \mathrm{dm}^{2}$ ), $a_{3}=-0.861$, and $A_{0}$ calculated by Eq. (13) (for $M \leqslant 50 \mathrm{stems} / \mathrm{dm}^{2}$ ) or by Eq. (14) (for $M$ $\geqslant 280$ stems $/ \mathrm{dm}^{2}$ ) - the mean flow velocity and corresponding discharge can be determined.

Further research should be carried out in the range of $50<M<280 \mathrm{stems} / \mathrm{dm}^{2}$, where a transitional behavior from the condition of low to high concentrations can be hypothesized and where the discriminant concentration $M^{*}$ occurs.

\section{Conclusions}

In a torrential stream, characterized by an exuberant vegetation both on the bed and on the banks, the evaluation of the flow resistance law has to take into account the dissipative effects due to the presence of vegetal elements determining the channel roughness. This evaluation strongly depends on the hydraulic behavior of the vegetation that can assume a rigid configuration or a flexible one and, with reference to the water depth, it can be emergent or submerged. For flexible vegetation, the evaluation of the flow resistance law clashes with the difficulty to both estimate-for each examined hydraulic condition-the bent vegetation height and to adequately take into account the influence of the vegetal elements' concentration. In this paper, Kouwen's method was reviewed first. Characterizing the vegetation elements from a biomechanics point of view, the method introduces the so-called "aggregate stiffness" that takes into account both the concentration and the bending stiffness of the elements.

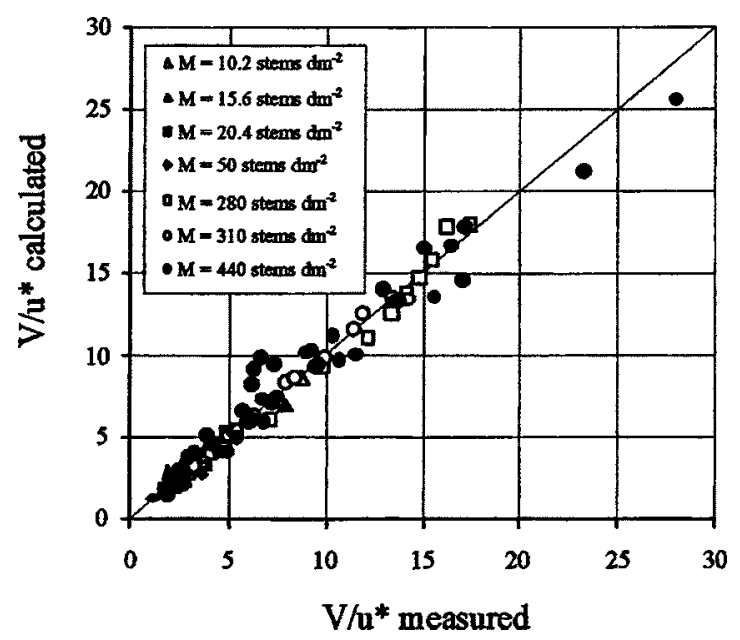

Fig. 16. Comparison between the measured values of $V / u^{*}$ and those calculated by Eq. (12) using coefficients listed in Table 7
Using some experimental data collected in a laboratory channel with a bed covered with submerged grass vegetation, the developed analysis highlighted that Kouwen's method produces a systematical overestimation of flow resistance. The overestimation increases with the concentration of the vegetal elements. For obtaining good agreement with the experimental data, the method needed calibration; in particular, the coefficients appearing in the semilogarithm flow resistance law were re-estimated.

Applying the Riabucinski-Buckingam theorem and the incomplete self-similarity condition, a new flow resistance law was deduced. This law established that the friction factor can be estimated by the shear Reynolds number, the relative submergence, and the degree of vegetation inflection.

The four coefficients appearing in this law have been estimated using all of the available measurements corresponding to four vegetation concentrations $(50,280,310$, and $440 \mathrm{stems} / \mathrm{dm}^{2}$ ). The estimation has been carried out by imposing that only the scale factor $A_{0}$ of the flow resistance law depends on the vegetation concentration. Previous studies highlighted that for high concentration values the flow velocity inside the vegetated layer is strongly reduced. The developed analysis showed that for high concentration values the study of the dissipative phenomena has to take into account the shear Reynolds number. For low concentration values, the estimate of the friction factor can be obtained by the relative submergence and the vegetation inflection degree. For high concentration values (greater then $50 \mathrm{stems} / \mathrm{dm}^{2}$ ), the analysis showed that the dimensionless term $u^{*} h_{s} / v$ also has to be considered in the flow resistance law. For both cases (low and high concentrations), two equations for estimating the scale factor $A_{0}$ of the flow resistance Eq. (12) were deduced.

Further research should be carried out in the range $50<M$ $<280$ stems $/ \mathrm{dm}^{2}$ for investigating the transitional behavior from the condition of "low" to "high" concentrations and for establishing the discriminant concentration value.

\section{Acknowledgment}

This research is supported by a grant from the Ministero Univ. e Ricerca Scientifica e Tecnologica, Governo Italiano, ex quota $60 \%$.

\section{Notation}

$$
\begin{aligned}
A_{0} & =\text { numerical coefficient; } \\
a_{1}, a_{2}, a_{3} & =\text { numerical coefficients of Eq. (12); } \\
B_{v} & =\text { dimensionless group; }
\end{aligned}
$$




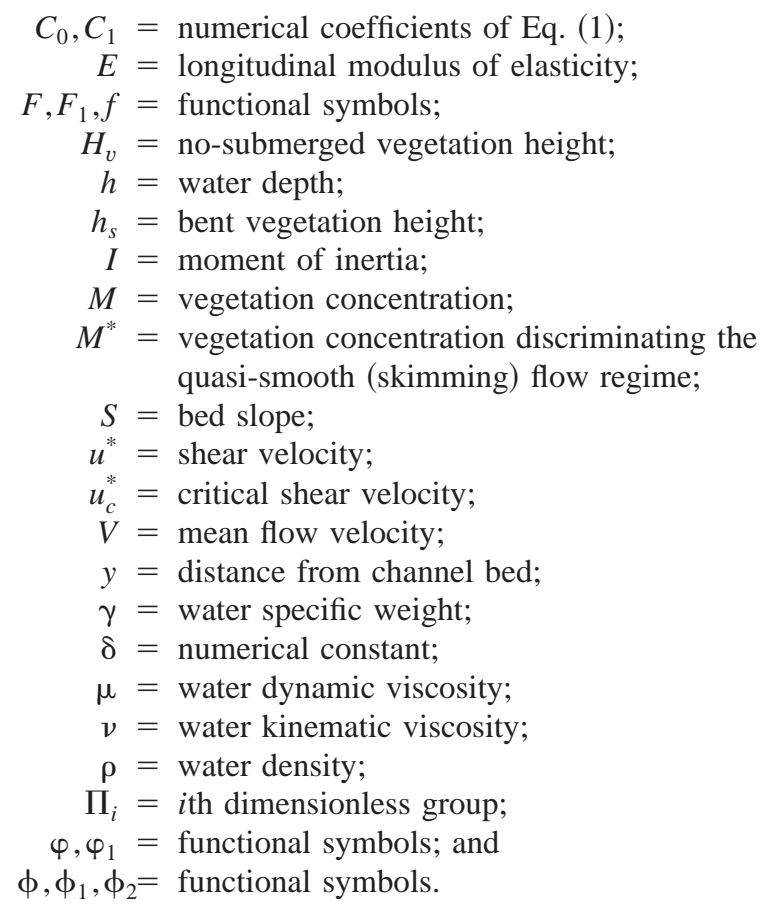

\section{References}

Armanini, A., and Righetti, M. (1998). "Resistenza al moto in alvei vegetati a scabrezza eterogenea." Proc., 26th Convegno di Idraulica e Costruzioni Idrauliche, CUECM, Catania, Italy, 3-14 (in Italian).

ASCE. (1963). "Friction factors in open channels-Progress report of the Task Force on friction factors in open channels of the Committee on Hydromechanics of the Hydraulics Division." J. Hydraul. Div., Am. Soc. Civ. Eng., 89(2), 97-146.

Baiamonte, G., and Ferro, V. (1997). "The influence of roughness geometry and Shields parameter on flow resistance in gravel bed channels." Earth Surf. Processes Landforms 22, 759-772.

Barenblatt, G. I. (1979). Similarity, self-similarity, and intermediate asymptotics, Consultants Bureau, N.Y.

Barenblatt, G. I. (1987). Dimensional analysis, Gordon and Breach, Newark, N.J.

Barenblatt, G. I. (1993). "Scaling laws for fully developed turbulent shear flows. 1: Basic hypothesis and analysis." J. Fluid Mech., 248, 513520.

Blench, T. (1961). "Discussion on 'Roughness spacing in rigid open channel' by W. W. Sayre and M. L. Albertson." J. Hydraul. Div., Am. Soc. Civ. Eng., 87(6), 251-257.

Carollo, F. G., Ferro, V., and Termini, D. (2002). "Flow velocity measurement in vegetated channels." J. Hydraul. Eng. 128(7), 664-673.

Darby, S. E. (1999). "Modeling effect of riparian vegetation on flow resistance and flood potential." J. Hydraul. Eng. 125(5), 443-454.

Darby, S. E., and Thorne, C. R. (1996). "Predicting stage-discharge curves in channels with bank vegetation." J. Hydraul. Eng. 122(10), 583-586.

Eastgate, W. I. (1966). "Vegetated stabilization of grassed waterways and dam bywashes."MS thesis,Univ. of Queensland, St. Lucia, Queensland, Australia.

Fenzl, R. N., and Davis, J. R. (1964). "Hydraulic resistance relationships for surface flows in vegetated channels." Trans. ASAE, 7(1), 46-55.

Ferro, V. (1997). "Applying hypothesis of self-similarity for flowresistance law of small-diameter plastic pipes." J. Irrig. Drain. Eng. 123(3), 175-179.

Ferro, V. (1999). "Evaluating the friction factor for gravel-bed channel with high boulder concentration." J. Hydraul. Eng. 125(7), 771-778.
Ferro, V. (2002). "La sistemazione dei bacini idrografici." McGraw-Hill, Milano, Italy (in Italian).

Ferro, V., and Giordano, G. (1990). "Esperienze sulle resistenze al moto in alvei di tipo montano: riesame critico e nuove acquisizioni." Riv. Ingeg. Agrar, 2, 83-98 (in Italian).

Ferro, V., and Giordano, G. (1991). "Experimental study of flow resistance in gravel-bed rivers." J. Hydraul. Eng., 117(10), 1239-1246.

Ferro, V., and Giordano, G. (1992). "Valutazione sperimentale delle resistenze al moto in alvei con vegetazione rigida sul fondo in condizioni di macroscabrezza." Quad. Idronom. Montana, 11/12, 163-181 (in Italian).

Ferro, V., and Pecoraro, R. (2000). "Incomplete self-similarity and flow velocity in gravel-bed channels." Water Resour. Res. 36(9), 27612769.

Gourlay, M. R. (1970). "Discussion of "Flow retardance in vegetated channels' by N. Kouwen, T. E. Unny, and H. M. Hill.” J. Irrig. Drain. Eng., 96(3), 351-357.

Ikeda, S., and Kanazawa, M. (1996). "Three-dimensional organized vortices above flexible water plants." J. Hydraul. Eng. 122(11), 634640.

Johnson, J. W. (1942). "The importance of considering side-wall friction in bed load investigation." Civ. Eng. (N.Y.) 12(6), 329-331.

Kouwen, N. (1988). "Field estimation of the biomechanical properties of grass." J. Hydraul. Res., 26(5), 559-568.

Kouwen, N. (1992). "Modern approach to design of grassed channels." $J$. Irrig. Drain. Eng., 118(5), 733-743.

Kouwen, N., and Harrington, R. A. (1974). "A criterion for vegetation stiffness." Agricultural and Urban Consideration in Irrigation and Drainage, ASCE, Reston, Va., 273-284.

Kouwen, N., and Li, R. M. (1980). "Biomechanics of vegetated channel linings.” J. Hydraul. Div., Am. Soc. Civ. Eng., 106(6), 1085-1103.

Kouwen, N., Li, R. M., and Simons, D. B. (1981). "Flow resistance in vegetated waterways." Trans. ASAE, 24(3), 684-698.

Kouwen, N., and Unny, T. E. (1973). "Flexible roughness in open channels." J. Hydraul. Div., Am. Soc. Civ. Eng., 99(5), 713-728.

Kouwen, N., Unny, T. E., and Hill, H. M. (1969). "Flow retardance in vegetated channels." J. Irrig. Drain. Eng., 95(2), 329-344.

Kowobary, T. S., Rice, C. E., and Garton, J. E. (1972). "Effect of roughness elements on hydraulic resistance for overland flow." Trans. ASAE, 15(5), 979-984.

Longo, C. (1997). "Biologia vegetale: Forme e funzioni." Utet, Torino, Italy (in Italian).

Masterman, R., and Thorne, C. R. (1992). "Predicting stage-discharge curves in channels with bank vegetation." J. Hydraul. Eng. 122(10), 583-586.

Petryk, S., and Bosmajian, G., III (1975). "Analysis of flow trough vegetation." J. Hydraul. Div., Am. Soc. Civ. Eng., 101(7), 871-884.

Raffaelli, S., Domenichini, F., and Solari, L. (2002). "Resistenza al moto in un alveo vegetato: Indagine sperimentale di laboratorio." Proc., 28th Convegno di Idraulica e Costruzioni Idrauliche, Bios, Cosenza, Italy, 223-230 (in Italian).

Rouse, H. (1965). "Critical analysis of open-channel resistance." J. Hydraul. Div., Am. Soc. Civ. Eng., 91(4), 1-26.

Shen, H. W. (1973). "Flow resistance over short simulated vegetation and various tall simulated vegetation groupings on flow resistance and sediment yield." Environmental Impact on Rivers (Rivers Mechanics III, Fort Collins, Colo).

Stoller, J., and Lemon, E. R. (1963). "Turbulent transfer characteristics of the airstream in and above the vegetative canopies at the earth surface. The energy budget at the earth surface, Part II." E. R. Lemon, ed., Production Res. Rep. No. 72, Agricultural Research Service, U.S. Dept. of Agriculture, Washington, D.C., 34-35.

Stone, B. M., and Shen, H. T. (2002). "Hydraulic resistance of flow in channels with cylindrical roughness." J. Hydraul. Eng. 128(5), 500506.

Wilson, C. A. M. E., and Horritt, M. S. (2002). "Measuring the flow resistance of submerged grass." Hydrolog. Process., 16, 2589-2598. 